\title{
Design and synthesis of soluble dibenzosuberane-substituted fullerene derivatives for bulk-heterojunction polymer solar cells
}

\author{
Tao Yang ${ }^{a}$, Zuoquan Jiang ${ }^{\mathrm{a}, *}$, Xiaodong Huang ${ }^{\mathrm{a}}$, Huaixin Wei ${ }^{\mathrm{a}}$, Jianyu Yuan ${ }^{\mathrm{a}}$, Wei Yue ${ }^{\mathrm{b}}$, \\ Youyong $\mathrm{Li}^{\mathrm{a}}$, Wanli Ma ${ }^{\mathrm{a}, *}$ \\ ${ }^{a}$ Institute of Functional Nano E' Soft Materials (FUNSOM), Soochow University, 199 Ren'ai Road, Suzhou 215123, PR China \\ ${ }^{\mathrm{b}}$ Department of Biotechnology, Chemistry, and Environmental Engineering, Aalborg University, Sohngaardsholmsvej 57, DK-9000 Aalborg, Denmark
}

\section{A R T I C L E I N F O}

\section{Article history:}

Received 3 April 2013

Received in revised form 6 May 2013

Accepted 11 May 2013

Available online 2 June 2013

\section{Keywords:}

Fullerene derivatives

Dibenzosuberane

Morphology

Polymer solar cells

\begin{abstract}
A B S T R A C T
Two new dibenzosuberane-substituted fullerene derivatives, dibenzosuberane- $\mathrm{C}_{60}$ monoadduct (DBSCMA) and bis-adduct (DBSCBA) were synthesized using a classical cyclopropanation reaction via a tosylhydrazone route for application as acceptor materials in polymer solar cells (PSCs). DBSCBA shows good solubility in common organic solvents and both derivatives were characterized by ${ }^{1} \mathrm{HNMR},{ }^{13} \mathrm{C}$ NMR, MALD-TOF, elemental analysis and UV-vis absorption measurements. The shift of fullerene energy levels induced by the dibenzosuberane substitution was investigated by using theoretical simulations and ultraviolet photoelectron spectroscopy. Bulk-heterojunction PSCs based on poly (3-hexylthiophene) (P3HT) and dibenzosuberane- $\mathrm{C}_{60}$ derivatives were fabricated and optimized by adjusting the donor/acceptor ratio and using thermal annealing and solvent additive. The morphologies of the active layers processed under different conditions were also examined by atomic force microscopy. When tested under an illumination of AM $1.5 \mathrm{G}$ at $100 \mathrm{~mW} /$ $\mathrm{cm}^{2}$, the highest power conversion efficiency of the devices using DBSCBA is $3.70 \%$ which is superior to that of conventional P3HT:PCBM devices.
\end{abstract}

(C) 2013 Elsevier B.V. All rights reserved.

\section{Introduction}

Bulk-heterojunction (BHJ) polymer solar cells (PSCs) have become one of the hottest research fields in recent years because of their unique advantages such as solution process, light weight and the possibility for transparent, flexible devices [1-5]. In a conventional BHJ PSC, the active layer is sandwiched between a transparent indium tin oxide (ITO) anode and a low-work-function metal cathode and comprises of a conjugated polymer as donor and a fullerene derivative as acceptor. One of the most popular compositions in BHJ PSCs is the blend of poly(3-hexylthiophene) (P3HT) and [6,6]-phenyl- $\mathrm{C}_{61}$-butyric acid ester (PCBM) [6]. To date, the power conversion efficiency

\footnotetext{
* Corresponding authors. Tel.: +86 51265880951.

E-mail address: wlma@suda.edu.cn (W. Ma).
}

(PCE) of the optimized PSCs based on P3HT/PCBM has exceeded $4 \%[7,8]$. To further improve the device performance, novel conjugated polymers have been synthesized to achieve low bandgap, broad absorption, enhanced electron mobility and optimal energy levels [9-16]. Likewise, the research efforts toward new fullerene derivatives are equally important. As electron acceptor, conventional PCBM has some well-known drawbacks, such as weak absorption in the visible region and a low-lying LUMO (Lowest Unoccupied Molecular Orbital) energy level, leading to significant loss of open circuit voltage $\left(V_{\text {oc }}\right)$. To address the question, numerous PCBM-like fullerene derivatives have been studied as electron acceptors [1726], most of which, however, showed poor or just comparable performance to PCBM. Recently, the development of fullerene bis-adduct acceptors for higher $V_{\text {oc }}$ PSCs has received considerable attention [27-35]. Successful exam- 
ples such as [6,6]-phenyl- $\mathrm{C}_{61}$-butyric acid methyl ester bisadduct (bis- $\mathrm{PC}_{61} \mathrm{BM}$ ) [27], indene- $\mathrm{C}_{60}$ bis-adduct (ICBA) [29], dihydro-naphthyl- $\mathrm{C}_{60}$ bis-adduct (NCBA) [30], di(4methylphenyl)-methano- $\mathrm{C}_{60}$ bis-adduct (DMPCBA) [31], bis-adduct thieno-o-uinodimethane- $\mathrm{C}_{60}$ (bis-TOQC) [32] have been reported. Although remarkable progress has been made, the influence of multi-adduct functional groups on the photovoltaic performances are still unclear. The exploration of new fullerene derivatives and the investigation of their structure-property relationships are still critical [19]. In this work, we firstly introduced the spirostructure to three-membered ring group on the fullerene acceptor to investigate the effect of this new structure on the acceptor photovoltaic performance. We designed and synthesized two new acceptors dibenzosuberane- $C_{60}$ mono-adduct (DBSCMA) and its bis-adduct (DBSCBA) through the cyclopropanation reaction (as shown in Scheme 1).Our results showed that the close ring did not interfere with the reaction activity and good yields were obtained. The bis-adduct DBSCBA shows good solubility in common solvents such as chloroform, toluene, chlorobenzol and $o$-dichlorobenzene, while the mono-adduct DBSCMA is less soluble. Their LUMO and HOMO (Highest Occupied Molecular Orbital) energy levels were carefully investigated by using theoretical simulations and ultraviolet photoelectron spectroscopy. When tested under an illumination of AM $1.5 \mathrm{G}$ at $100 \mathrm{~mW} / \mathrm{cm}^{2}$, a high PCE of $3.70 \%$ was obtained for the optimized devices using DBSCBA, which is nearly $\sim 10 \%$ higher than that of the devices using PCBM.

\section{Experimental section}

\subsection{Materials and measurement}

$\mathrm{C}_{60}$ was purchased from Puyang Yongxin Fullerene Co., Ltd. Other reagents and chemicals were purchased from

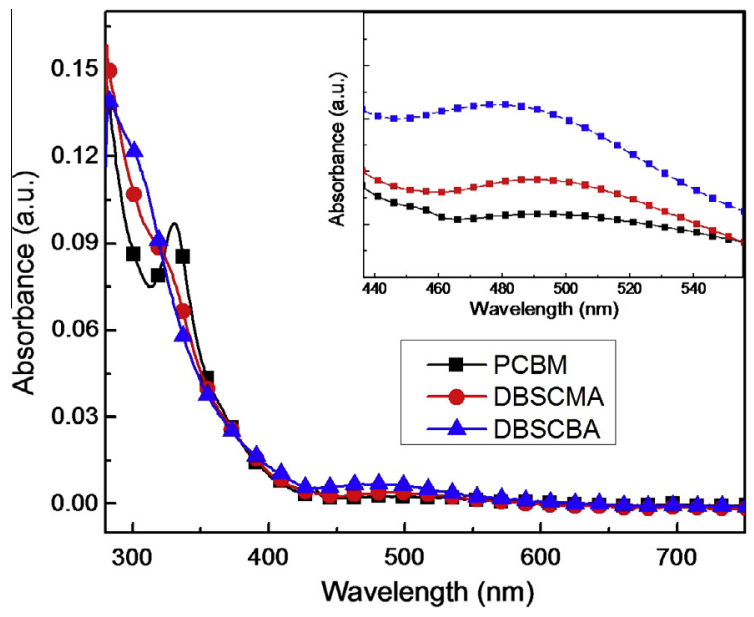

Fig. 1. The UV-vis absorptions spectra of PCBM, DBSCMA and DBSCBA in chlorobenzene solutions. The inset is the enlarged absorption spectra in the visible region from 440 to $550 \mathrm{~nm}$.

Alfa-Aesar Co. or Sigma-Aldrich Co. and used as received without further purification. Dibenzosuberone $p$-tosylhydrazone (1) was synthesized according to the literature [17]. ${ }^{1} \mathrm{H}$ NMR and ${ }^{13} \mathrm{C}$ NMR spectra were measured on a Varian Unity Inova $400 \mathrm{MHz}$ and a Varian NMR system $300 \mathrm{MHz}$ spectrometer with tetramethylsilane(TMS; $\delta=0 \mathrm{ppm}$ ) as the internal standard, respectively. UV-vis absorption spectra were obtained on a Perkin Elmer model Lambda 750 instrument. Ultraviolet photoelectron spectroscopy (UPS) measurements were performed in a KRATOSULTRA-DLD ultrahigh vacuum surface analysis system. The spectra were measured by using an unfiltered He I (21.22 eV) gas discharge lamp and a total instrumental energy resolution of $100 \mathrm{meV}$. Atomic force microscopy (AFM) was performed with a Veeco Multimode V instrument in tapping mode.<smiles>Cc1ccc(S(=O)(=O)NN=C2c3ccccc3CCc3ccccc32)cc1</smiles>

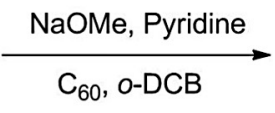<smiles>O=C1c2ccccc2CCc2ccccc21</smiles>

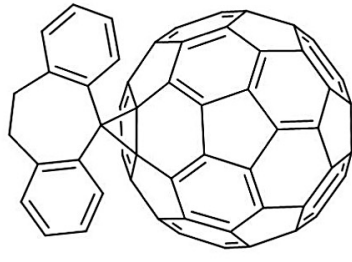

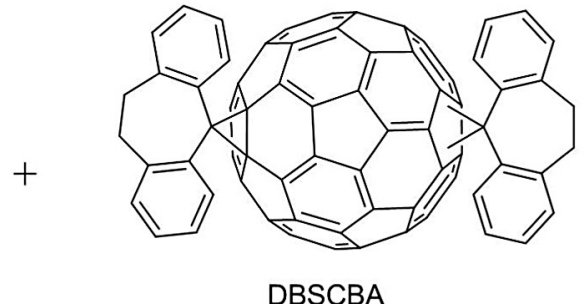

DBSCMA

Scheme 1. Synthetic routes and chemical structures of DBSCMA and DBSCBA. 


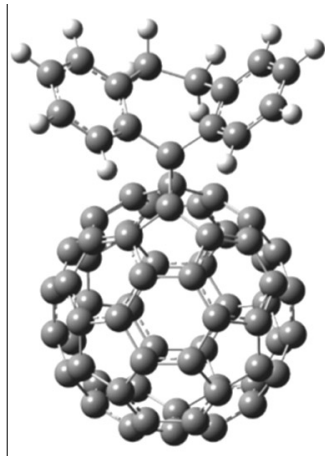

DBSCMA
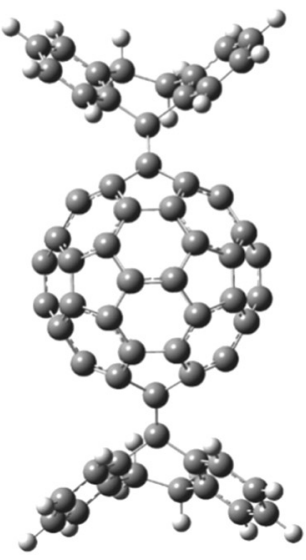

DBSCBA

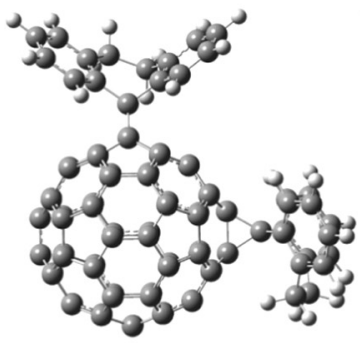

DBSCBA

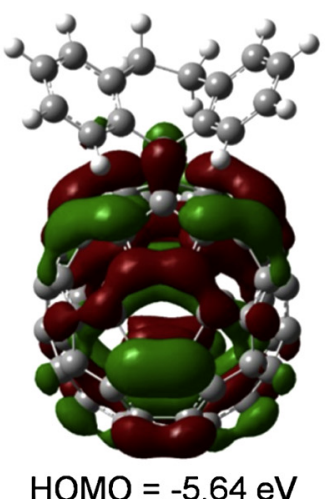

$\mathrm{HOMO}=-5.64 \mathrm{eV}$

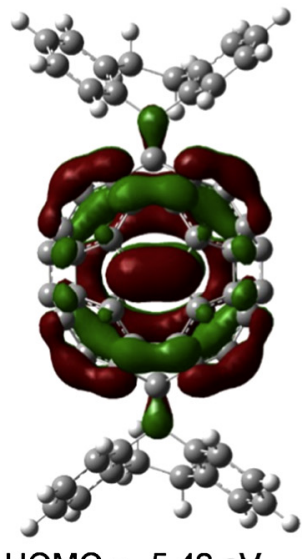

$\mathrm{HOMO}=-5.42 \mathrm{eV}$

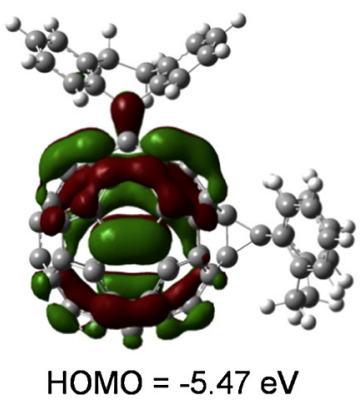

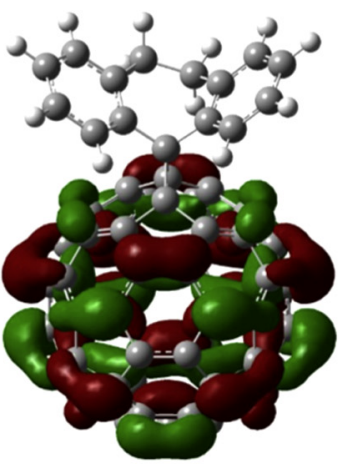

LUMO $=-3.16 \mathrm{eV}$
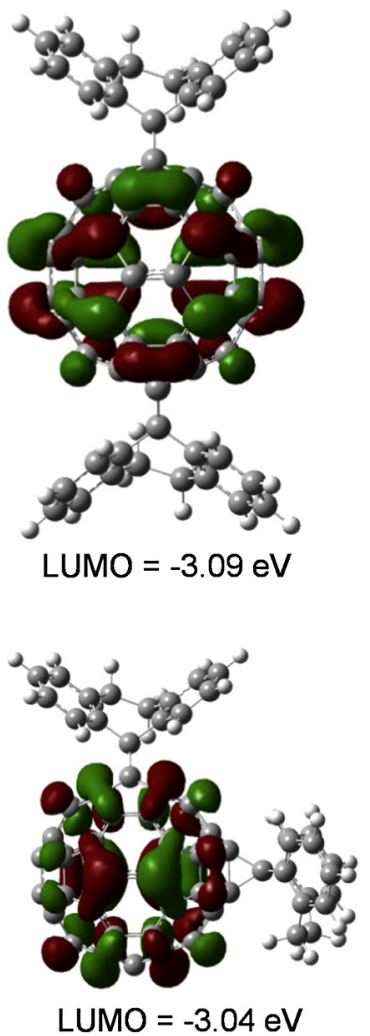

Fig. 2. Molecular geometries and orbital surfaces of the HOMO and LUMO of DBSCMA and DBSCBA. obtained at the DFT/B3LYP/6-31G* level

\subsection{Fabrication and characterization of PSCs}

PSCs using P3HT as the donor and PCBM, DBSCMA and DBSCBA as the acceptors were fabricated, with a typical structure of ITO/PEDOT:PSS/P3HT:acceptor/LiF/Al. The solutions were prepared in 1,2-dichlorobenzene with different polymer:fullerene ratios (with a total concentration of $20 \mathrm{mg} / \mathrm{mL}$ ). The ITO-coated glass substrates were cleaned by sequential ultrasonic treatment in detergent, deionized water, acetone, and isopropyl alcohol, and then dried .After UV ozone treatment of the ITO substrates for $20 \mathrm{~min}$, about $40 \mathrm{~nm}$ thick poly(ethylenedioxythio- phene):poly(styrenesulfonic acid)(PEDOT:PSS) layer was spin-coated from aqueous solution (4500 rpm for $40 \mathrm{~s}$ ) filtered through a $0.45 \mu \mathrm{m}$ poly(tetrafluoroethylene) (PTFE) filter. The PEDOT:PSS layer was baked on a hotplate at $150{ }^{\circ} \mathrm{C}$ for $10 \mathrm{~min}$. The pre-dissolved composite solution was spin coated on the PEDOT:PSS layer at $700 \mathrm{rpm}$. Finally, a top electrode consisting of a $0.6 \mathrm{~nm}$ LiF layer and a $100 \mathrm{~nm}$ Al layer was deposited on the polymer active layer under a vacuum of $2 \times 10^{-6}$ Torr , the active area of the devices is $7.25 \mathrm{~mm}^{2}$. The current density-voltage characteristics $(J-V)$ of the photovoltaic cells were measured using a Keithley 2400 digital source meter under a simulated AM 


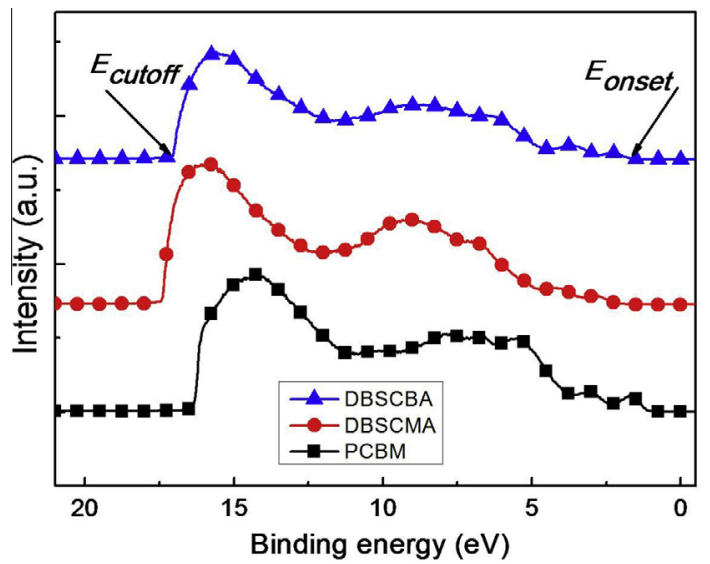

Fig. 3. UPS spectra of PCBM, DBSCMA and DBSCBA films on ITO surface.

$1.5 \mathrm{G}$ solar irradiation at $100 \mathrm{~mW} \mathrm{~cm}^{-2}$ (Newport, Class AAA solar simulator, 94023A-U). The light intensity is calibrated by a certified Oriel Reference Cell (91150V).

\subsection{Synthesis}

\subsubsection{Synthesis of dibenzosuberonep-tosylhydrazone (1)}

Dibenzosuberone (1.04 g, $5.0 \mathrm{mmol}$ ) and p-toluene-sulfonylhydrazide $(1.40 \mathrm{~g}, 7.5 \mathrm{mmol}$ ) were dissolved in methanol $(20 \mathrm{ml})$, and a catalytic amount of concentrated hydrochloric acid was added to the mixture and refluxed overnight. After cooling to room temperature, the mixture was stirred over $24 \mathrm{~h}$ and then cooled to $-15^{\circ} \mathrm{C}$. The precipitated product was collected by filtration, washed with cold methanol and dried in a desiccator to yield tosylhydrazone compound $1(1.35 \mathrm{~g}, 70 \%)$ as a white crystal. ${ }^{1} \mathrm{H}$ NMR $\left(\mathrm{CDCl}_{3}, 400 \mathrm{MHz}, \mathrm{ppm}\right) 7.06-7.86$ (m, 12H), 7.25 (d, $2 \mathrm{H}), 3.19(\mathrm{t}, 4 \mathrm{H}), 2.46(\mathrm{~s}, 3 \mathrm{H}) .{ }^{13} \mathrm{C} \mathrm{NMR}\left(\mathrm{CDCl}_{3}, 300 \mathrm{MHz}\right.$, ppm) 155.86, 144.29, 140.04, 138.43, 135.72, 135.39, $130.72,129.86,129.50,129.31,129.21,128.05,127.24$, 126.37, 126.21, 34.02, 31.75. MALD-TOF: 375.20.Calculated: C, 70.19\%; H, 5.35\%; N, 7.44\%. Found: C, 69.53\%; H, $5.25 \%$; N, $7.49 \%$.

\subsubsection{Synthesis of DBSCMA and DBSCBA}

NaOMe $(0.08 \mathrm{~g}, 1.5 \mathrm{mmol})$ was added to a stirred solution of $1(0.38 \mathrm{~g}, 1 \mathrm{mmol})$ in dry pyridine $(10 \mathrm{ml})$ under $\mathrm{N}_{2}$ atmosphere. After stirring for $15 \mathrm{~min}$ at $80^{\circ} \mathrm{C}$, the reaction mixture was treated with a solution of $C_{60}(0.36 \mathrm{~g}$, $0.5 \mathrm{mmol})$ in 1,2-dichlorobenzene $(30 \mathrm{ml})$ and stirred for $24 \mathrm{~h}$. Afterwards, the solution was heated to reflux for
$24 \mathrm{~h}$. After cooling to room temperature, the solution was loaded into silica column and then purified by flash silica column chromatography with 1:3 toluene/hexane as the eluents. Then, the fraction containing DBSCMA was collected and concentrated. The concentration solution was poured into methanol to give $\operatorname{DBSCMA}(0.10 \mathrm{~g} 22 \%)$ as a dark brown solid. ${ }^{1} \mathrm{H}$ NMR $\left(\mathrm{CDCl}_{3}, 400 \mathrm{MHz}, \mathrm{ppm}\right) 7.15-$ $7.33(\mathrm{~m}, 8 \mathrm{H}), 2.35(\mathrm{~s}, 4 \mathrm{H}) .{ }^{13} \mathrm{C} \mathrm{NMR}\left(\mathrm{CDCl}_{3}, 400 \mathrm{MHz}\right.$, ppm) 146.67, 142.00, 141.80, 128.46, 125.60, 124.32, 98.82, 52.34, 37.64, 31.13. MALD-TOF: 912.4. Calculated: C, $98.68 \%$;, $1.32 \%$. Found: C, 96.75\%; H, 1.23\%. DBSCBA and DBSCMA were separated and purified from the same reaction product mixture. The fraction containing DBSCBA was collected and concentrated. The concentration solution was poured into methanol to give DBSCBA ( $0.16 \mathrm{~g} 28$ \%) as a dark brown solid. ${ }^{1} \mathrm{H}$ NMR $\left(\mathrm{CDCl}_{3}, 400 \mathrm{MHz}, \mathrm{ppm}\right)$ 6.87-8.34 (m, 16H), 3.09-4.62 (m, 8H). ${ }^{13} \mathrm{C} \mathrm{NMR}\left(\mathrm{CDCl}_{3}\right.$, $300 \mathrm{MHz}, \mathrm{ppm}) 163.11,148.18,145.68,144.70,143.02$, $141.95,140.82,139.04,137.80,131.61,130.28,128.83$, 125.12, 109.07, 94.25, 53.61, 32.08. MALD-TOF: 1104.50. Calculated: C, 97.81\%; H, 2.19\%. Found:C, 93.83\%; H, 2.15\%.

\section{Results and discussion}

\subsection{Synthesis and optical properties}

Cyclopropanation is a classic reaction for fullerene modification, due to its high stability and small structural perturbation [17]. The two new fullerene derivatives were synthesized via the reaction which is similar to the synthesis of PCBM. The structures of DBSCMA and DBSCBA were confirmed by the ${ }^{1} \mathrm{HNMR},{ }^{13} \mathrm{CNMR}$ spectra, MALD-TOF mass spectrum and elemental analysis. The synthetic route is shown in Scheme 1. The UV-vis absorption spectra of $\mathrm{PC}_{60} \mathrm{BM}$, DBSCMA and DBSCBA in dichloromethane solutions (the absorption spectrum of $\mathrm{PC}_{60} \mathrm{BM}$ is for comparison) are shown in Fig. 1 . All the three $C_{60}$ derivatives display strong UV absorption peaks ranging from 200 to $400 \mathrm{~nm}$, while their visible absorptions are generally weak. It is worth noting that the absorbance of DBSCMA and DBSCBA are slightly higher than that of $\mathrm{PC}_{60} \mathrm{BM}$ in the visible region (see the inset of Fig. 1), which may influence the short-circuit current of the corresponding polymer solar cells.

\subsection{DFT calculations and UPS measurement}

To better understand the effect of dibenzosuberanesubstitution on the fullerene energy levels, density functional theory (DFT) calculations were carried out at the

Table 1

Energy levels obtained from theoretical and experimental results.

\begin{tabular}{|c|c|c|c|c|c|c|}
\hline & \multicolumn{3}{|c|}{ Experimental values $^{\mathrm{a}}$} & \multicolumn{3}{|c|}{ Theoretical values $^{\mathrm{b}}$} \\
\hline & HOMO $(\mathrm{eV})$ & LUMO $(\mathrm{eV})$ & $E_{\mathrm{g}}(\mathrm{eV})$ & HOMO $(\mathrm{eV})$ & LUMO $(\mathrm{eV})$ & $E_{\mathrm{g}}(\mathrm{eV})$ \\
\hline PCBM & 5.81 & 3.80 & 2.01 & 5.78 & 3.20 & 2.58 \\
\hline DBSCMA & 5.85 & 3.75 & 2.10 & 5.64 & 3.16 & 2.48 \\
\hline DBSCBA & 5.76 & 3.68 & 2.08 & 5.42 & 3.09 & 2.33 \\
\hline
\end{tabular}

a HOMO values were determined by UPS, while LUMO values were estimated by subtracting from optical bandgap $E_{\mathrm{g}}$.

b All chemical structures were optimized with the B3LYP function and a basis set of 6-31G. 
B3LYP/6-31G* level. The wave functions of the frontier molecular orbital of the two derivatives are depicted in Fig. 2. Compared with the mono-substitution on DBSCMA, the bis-substitution on DBSCBA further breaks the conjugation of the carbon cage, leading to less extended delocalization of the $\pi$ electrons. Consequently, the HOMO and LUMO energy levels of DBSCBA were calculated to be $-5.42 \mathrm{eV}$ and $-3.09 \mathrm{eV}$ respectively, which are both higher than the calculated values of DBSCMA (HOMO: -5.64 , LUMO: $-3.16 \mathrm{eV}$ ) and PCBM (HOMO: -5.78, LUMO: $-3.20 \mathrm{eV}$ ), indicating a possible higher $V_{\mathrm{oc}}$. It is worth noting that the relative position of the two substitution groups on the fullerene will also influence the calculated energy levels, as shown in Fig. 2.

Experimentally, the HOMO level can be measured by UPS and the LUMO level can be calculated by subtracting the optical gap (obtained from Fig. 1) from the measured HOMO level. Fig. 3 shows the UPS spectra taken from pristine thin films of $\mathrm{PC}_{60} \mathrm{BM}$, DBSCMA and DBSCBA on ITO substrates. The HOMO energy levels are determined by the following equation:

$E_{\text {номо }}=h v-\left(E_{\text {cutoff }}-E_{\text {onset }}\right)$

where $h v$ is the incident photon energy of $21.2 \mathrm{eV}$, the positions of $E_{\text {cutoff }}$ and $E_{\text {onset }}$ are marked in Fig. 3, respectively. The measured HOMO values are $-5.81 \mathrm{eV}$ for $\mathrm{PC}_{60}$ BM, $-5.85 \mathrm{eV}$ for DBSCMA and $-5.76 \mathrm{eV}$ for DBSCBA within the error range of $\pm 0.04 \mathrm{eV}$. The detailed values of the HOMO, LUMO and optical gap are summarized in Table 1 . Based on the data, although there is a discrepancy between the measured and theoretically calculated values, the shift of fullerene LUMO measured by UPS is consistent with the simulation results. Therefore, the introduced dibenzosuberane groups can not only endow the fullerene with solubility but also with improved energy level alignment for potentially higher $V_{\text {oc }}$.

\subsection{Photovoltaic properties}

The photovoltaic properties of the fullerene derivatives were studied by fabricating PSCs with the structure of ITO/ PEDOT:PSS/P3HT: fullerene/LiF/Al, where the polymer P3HT was used as electron donor and fullerene derivatives were used as electron acceptors. The $J-V$ curves of the PSCs are presented in Fig. 4, and the photovoltaic parameters of the devices are listed in Table 2. In order to get high device performance, we employed different optimization methods such as thermal annealing, adjusting D/A ratio and using solvent additive. According to the previous study, thermal annealing was one of the most efficient methods for improving device performance [8]. Thus we firstly optimized the annealing temperature of the devices using DBSCBA as the acceptor and $o$-DCB as the solvent. The annealing temperatures were adjusted from $90{ }^{\circ} \mathrm{C}$ to $150^{\circ} \mathrm{C}$, and we observed that the best performance was achieved at $110^{\circ} \mathrm{C}$, with the device PCE increased from $1.21 \%$ (with no annealing) to $2.15 \%$. The result is in line with the earlier study, in which the optimal annealing temperature was also considered as $110^{\circ} \mathrm{C}$ for $\mathrm{P} 3 \mathrm{HT} / \mathrm{PC}_{60} \mathrm{BM}$ devices cast from $o$-DCB solution [3]. Secondly, the D/A composite ratios are found critical for PSC performance
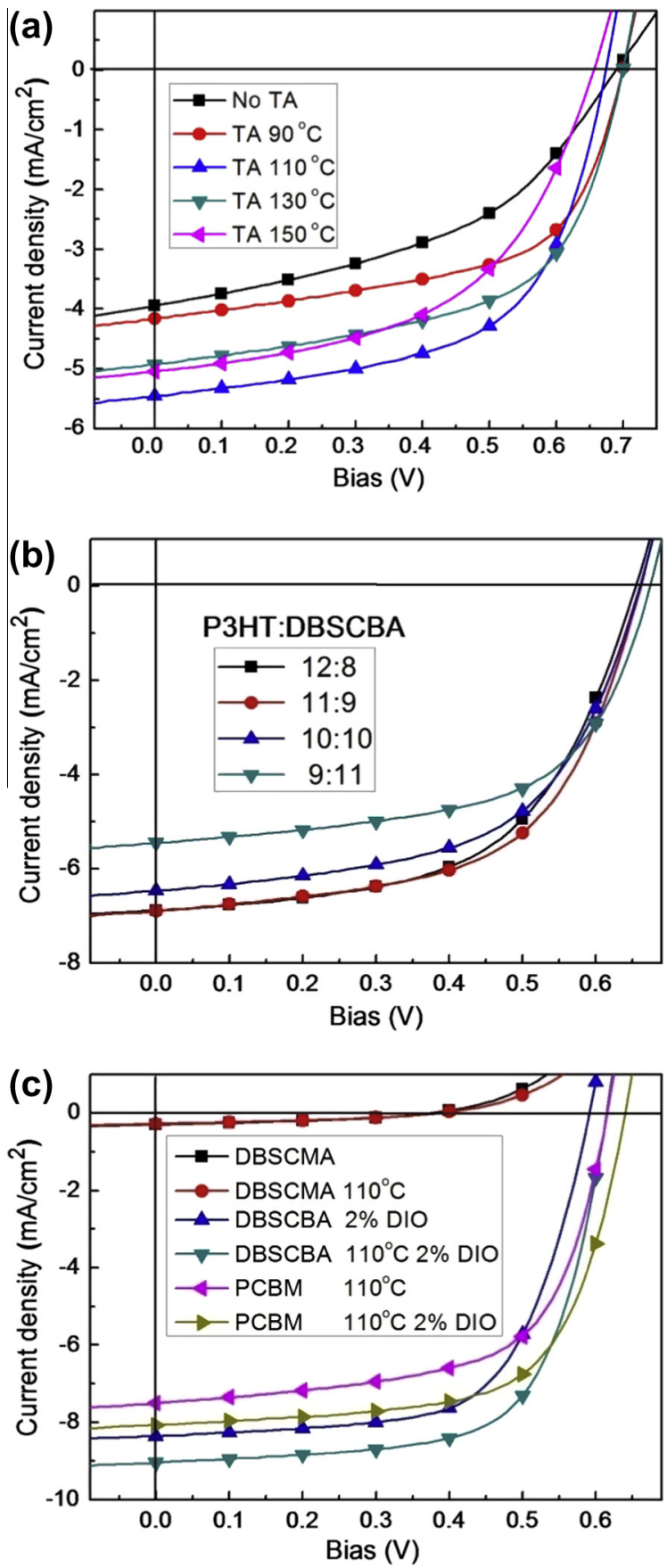

Fig. 4. $J-V$ curves of devices under different annealing temperatures (a), with different $\mathrm{D} / \mathrm{A}$ ratios (b) and with the addition of solvent additive (c).

[36]. To investigate the effect of $\mathrm{D} / \mathrm{A}$ ratio on the device photovoltaic performance, we fabricated PSCs with P3HT:DBSCBA weight ratios of 9:11, 10:10, 11:9 and 12:8 (with a total concentration of $20 \mathrm{mg} / \mathrm{ml}$ ), under an optimal annealing condition. The $J-V$ curves and the corresponding photovoltaic parameters of the PSCs are shown in Fig. 4b and Table 2, respectively. The device with a D/A weight ratio of $11: 9$ obtained the best PCE of $2.63 \%$, indicating that 11:9 is the optimal ratio for devices based on 
Table 2

Device performances of solar cells.

\begin{tabular}{|c|c|c|c|c|c|c|c|c|}
\hline Acceptor & Solvent & Blend ratio & Tem. $\left({ }^{\circ} \mathrm{C}\right)$ & DIO (\%) & $V_{\mathrm{oc}}(\mathrm{V})$ & $J_{\mathrm{sc}}\left(\mathrm{mA} \mathrm{cm}^{-2}\right)$ & $\mathrm{FF}(\%)$ & PCE (\%) \\
\hline DBSCBA & DCB & $9: 11$ & - & - & 0.68 & 3.93 & 45.3 & 1.21 \\
\hline DBSCBA & DCB & $9: 11$ & 90 & - & 0.69 & 4.15 & 58.7 & 1.68 \\
\hline DBSCBA & DCB & $9: 11$ & 110 & - & 0.67 & 5.45 & 58.9 & 2.15 \\
\hline DBSCBA & DCB & $9: 11$ & 130 & - & 0.69 & 4.91 & 58.2 & 1.97 \\
\hline DBSCBA & DCB & $9: 11$ & 150 & - & 0.69 & 5.03 & 52.1 & 1.70 \\
\hline DBSCBA & DCB & $12: 8$ & 110 & - & 0.65 & 6.88 & 56.4 & 2.52 \\
\hline DBSCBA & DCB & $11: 9$ & 110 & - & 0.66 & 6.88 & 57.8 & 2.63 \\
\hline DBSCBA & DCB & $10: 10$ & 110 & - & 0.66 & 6.46 & 56.2 & 2.40 \\
\hline DBSCBA & DCB & $9: 11$ & 110 & - & 0.67 & 5.45 & 58.9 & 2.15 \\
\hline DBSCMA & DCB & $11: 9$ & 110 & - & 0.37 & 0.30 & 38.6 & 0.04 \\
\hline DBSCMA & DCB & $11: 9$ & 110 & - & 0.38 & 0.28 & 38.1 & 0.04 \\
\hline DBSCBA & DCB & $11: 9$ & - & 2 & 0.59 & 8.35 & 64.3 & 3.17 \\
\hline DBSCBA & DCB & $11: 9$ & 110 & 2 & 0.61 & 9.04 & 67.0 & 3.70 \\
\hline PCBM & DCB & $11: 9$ & 110 & - & 0.61 & 7.49 & 63.4 & 2.90 \\
\hline РCBM & DCB & $11: 9$ & 110 & 2 & 0.62 & 8.26 & 66.9 & 3.43 \\
\hline
\end{tabular}
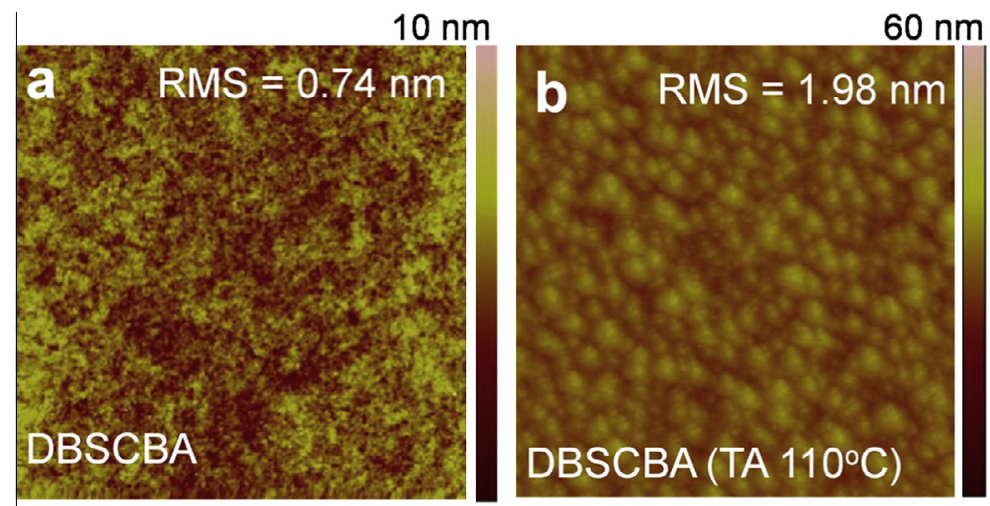

$80 \mathrm{~nm}$

$120 \mathrm{~nm}$
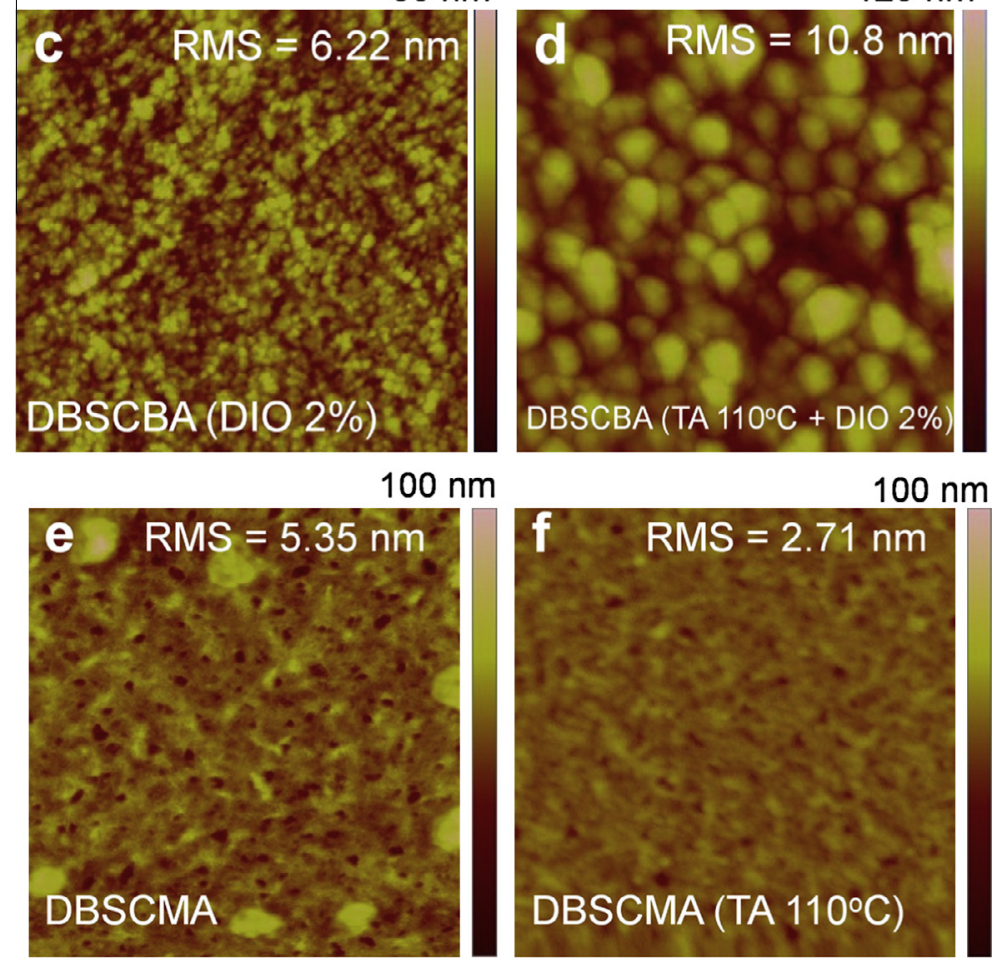

Fig. 5. AFM images of P3HT:DBSCBA film processed under different conditions. (a) as-cast (b) thermal annealed at $110{ }^{\circ} \mathrm{C}$ for 10 min (c) using $2 \%$ DIO, (d) applying both thermal annealing and solvent additive. P3HT:DBSCMA film morphology (e) as-cast and (f) thermal annealed at $110{ }^{\circ} \mathrm{C}$ for 10 min. 
P3HT:DBSCBA. Since the LUMO of DBSCBA is about $0.1 \mathrm{eV}$ higher than that of PCBM, a higher $V_{o c}$ is expected for devices using DBSCBA. Indeed, a $V_{\text {oc }}$ of $0.65-0.69 \mathrm{~V}$ was obtained for P3HT:DBSCBA devices processed under different conditions (Table 2), which is evidently higher than the $V_{\text {oc }}(0.61 \mathrm{~V})$ of PCBM based devices. To further improve device performance, the effect of solvent additive was investigated. Recently, solvent additives have been reported to enhance the device performance by improving the inter-penetrating D/A network structure $[37,38,41]$. Herein, we introduced a widely used additive 1,8-diiodooctane (DIO) and improved device performance was observed, as seen in Fig. 4c and Table 2. Dramatic PCE enhancement from $2.63 \%$ to $3.70 \%$ can be achieved for P3HT:DBSCBA devices with the addition of $2 \%$ DIO. This optimal device performance of P3HT:DBSCBA based devices is nearly $10 \%$ higher than that of the P3HT:PCBM devices (3.43\%) under the same processing conditions. The PCE improvement is mainly due to the photo-current enhancement, which can be attributed to the higher absorbance of DBSCBA than PCBM in the visible region. However, note that the $V_{\text {oc }}$ of P3HT:DBSCBA devices is reduced to $0.61 \mathrm{~V}$ after the use of DIO, which is consistent with the previous observation [34]b. Compared with DBSCBA, the mono-adduct DBSCMA shows very poor performance in PSCs with a low PCE of only $0.04 \%$, which is likely ascribed to the undesired film morphology (Fig. 5e) induced by its poor solubility. The excellent photovoltaic performance of P3HT:DBSCBA devices indicates that the new bis-adduct DBSCBA with spiro-structure is a promising material to replace conventional PCBM as acceptor in PSCs.

\subsection{Film morphologies}

As shown in Fig. 5, the effects of thermal annealing and additive on film morphology were investigated using atomic force microscopy (AFM). Before the use of thermal annealing and solvent additive, the pristine film does not show distinctive surface structures, implying limited phase separation and poor charge transport hindered by undeveloped D/A network (see Fig. 5a). After thermal annealing at $110{ }^{\circ} \mathrm{C}$ (Fig. $5 \mathrm{~b}$ ), grainy structures can be observed and the surface roughness alters from $0.74 \mathrm{~nm}$ to $1.98 \mathrm{~nm}$, indicating enhanced phase segregation and carrier transport [8], which is consistent with the corresponding PCE improvement from $1.21 \%$ (with no annealing) to $2.15 \%\left(110{ }^{\circ} \mathrm{C}\right)$. DIO is believed to allow a slower crystallization process during spin-coating, thus improving morphology through enhanced intermolecular ordering and well-developed phase separation [41]. Therefore we observed that film processed with DIO (Fig. 5c) exhibited fine phase separation domains and a striking difference of surface roughness altering from $0.74 \mathrm{~nm}$ to $6.22 \mathrm{~nm}$, leading to efficient charge transport and dramatically improved efficiency. As shown in Fig. 5d, when both thermal annealing and DIO were employed, the domain sizes further increased and a high roughness of $10.8 \mathrm{~nm}$ was observed. This roughness value is very close to that $(9.5 \mathrm{~nm})$ of the P3HT:PCBM device reported by Yang [39] and close to that $(7.9 \mathrm{~nm})$ of the best P3HT: $\mathrm{IC}_{60} \mathrm{BA}$ device [40]. The morphology of pris- tine P3HT:DBSCMA film is apparently different from P3HT:DBSCBA. As seen in Fig. 5e, large domains can be observed and the surface roughness is high $(5.35 \mathrm{~nm})$ compared to P3HT:DBSCBA $(0.74 \mathrm{~nm})$. In addition, we also observed huge micron level DBSCMA aggregates in such film under optical microscope. Most likely, the undesired morphology is caused by the poor solubility of DBSCMA, leading to poor device performance.

\section{Conclusions}

We have successful synthesized two fullerene derivatives, dibenzosuberane- $C_{60}$ mono-adduct (DBSCMA) and bis-adduct (DBSCBA) with new spiro-structure by cyclopropanation reaction for use as acceptor materials in polymer solar cells. The introduced dibenzosuberane groups improve the fullerene energy level alignment and the two new fullerene derivatives show slightly higher absorption in the visible region than conventional PCBM. After systematical optimization, a high power conversion efficiency of 3.70\% was obtained for the devices using DBSCBA under an illumination of AM $1.5 \mathrm{G}$ at $100 \mathrm{~mW} / \mathrm{cm}^{2}$, which is $10 \%$ higher than that of P3HT: PCBM control device. The improved PCE is attributed to the optimal morphology and enhanced absorbance of DBSCBA in the visible region.

\section{Acknowledgments}

This work was supported by the National High Technology Research and Development Program of China (863 Program) (Grant No. 2011AA050520), the National Natural Science Foundation of China (Grant No. 61176054), the Natural Science Foundation of Jiangsu Province of China (Grant No. SBK201122663).

\section{References}

[1] C.J. Brabec, N.S. Sariciftci, J.C. Hummelen, Adv. Funct. Mater. 11 (2001) 15.

[2] C.J. Brabec, S. Gowrisanker, J.J.M. Halls, D. Laird, S. Jia, S.P. Williams Adv. Mater. 22 (2010) 3839.

[3] G. Dennler, M.C. Scharber, C.J. Brabec, Adv. Mater. 21 (2009) 1323.

[4] A.C. Arias, J.D. MacKenzie, I. McCulloch, J. Rivnay, A. Salleo, Chem. Rev. 110 (2010) 3.

[5] M. Scharber, D. Mühlbacher, M. Koppe, P. Denk, C. Waldauf, A. Heeger, C. Brabec, Adv. Mater. 18 (2006) 789.

[6] G. Yu, J. Gao, J.C. Hummelen, F. Wudl, A.J. Heeger, Science 270 (1995) 1789.

[7] W. Cai, X. Gong, Y. Cao, Sol. Energy Mater. Sol. Cells 94 (2010) 114.

[8] W. Ma, C. Yang, X. Gong, K. Lee, A. Heeger, Adv. Funct. Mater. 15 (2005) 1617.

[9] (a) Y. Li, Acc. Chem. Res. 45 (2012) 723;

(b) H. Zhou, L. Yang, W. You, Macromolecules 45 (2012) 607; (c) P.M. Beaujuge, J.M.J. Fréchet, J. Am. Chem. Soc. 133 (2011) 20009

[10] (a) P. Morvillo, F. Parenti, R. Diana, C. Fontanesi, A. Mucci, F. Tassinari, L. Schenetti, Sol. Energy Mater. Sol. Cells 104 (2012) 45; (b) J.A. Mikroyannidis, D.V. Tsagkournos, S.S. Sharma, A. Kumar, Y.K. Vijay, G.D. Sharma, Sol. Energy Mater. Sol. Cells 94 (2010) 2318.

[11] L. Dou, J. You, J. Yang, C.-C. Chen, Y. He, S. Murase, T. Moriarty, K. Emery, G. Li, Y. Yang, Nat. Photonics 6 (2012) 180.

[12] L. Huo, J. Hou, Polym. Chem. 2 (2011) 2453.

[13] (a) H.X. Zhou, L.Q. Yang, A.C. Stuart, S.C. Price, S.B. Liu, W. You, Angew. Chem. Int. Ed. 50 (2011) 2995;

(b) Y. Liang, Z. Xu, J. Xia, S.T. Tsai, Y. Wu, G. Li, C. Ray, L. Yu, Adv. Mater. 22 (2010) E135.

[14] C. Piliego, T.W. Holcombe, J.D. Douglas, C.H. Woo, P.M. Beaujuge, J.M.J. Fréchet, J. Am. Chem. Soc. 132 (2010) 7595. 
[15] (a) A.T. Yiu, P.M. Beaujuge, O.P. Lee, C.H. Woo, M.F. Toney, J.M.J. Fréchet, J. Am. Chem. Soc. 134 (2011) 2180;

(b) S.C. Price, A.C. Stuart, L. Yang, H. Zhou, W. You, J. Am. Chem. Soc. 133 (2011) 4625.

[16] (a) L.J. Huo, S.Q. Zhang, X. Guo, F. Xu, Y.F. Li, J.H. Hou, Angew. Chem. Int. Ed. 50 (2011) 9697;

(b) Y. Huang, X. Guo, F. Liu, L. Huo, Y. Chen, T.P. Russell, C.C. Han, Y. Li, J. Hou, Adv. Mater. 24 (2012) 3383;

(c) Y. Huang, X. Guo, F. Liu, L. Huo, Y. Chen, T.P. Russell, C.C. Han, Y. Li, J. Hou, Adv. Mater. 23 (2012) 4636.

[17] J.C. Hummelen, B.W. Knight, F. LePeq, F. Wudl, J. Yao, C.L. Wilkins, J. Org. Chem. 60 (1995) 532.

[18] M.M. Wienk, J.M. Kroon, W.J.H. Verhees, J. Knol, J.C. Hummelen, P.A. van Hal, R.A.J. Janssen, Angew. Chem. Int. Ed. 42 (2003) 3371.

[19] Y. He, Y. Li, Phys. Chem. Chem. Phys. 13 (2011) 1970.

[20] Y. Zhang, H.-L. Yip, O. Acton, S.K. Hau, F. Huang, A.K.Y. Jen, Chem. Mater. 21 (2009) 2598.

[21] J.-C. Kuhlmann, P.D. Bruyn, R.K.M. Bouwer, A. Meetsma, P.W.M. Blom, J.C. Hummelen, Chem. Commun. 46 (2010) 7232

[22] J.H. Choi, K.-I. Son, T. Kim, K. Kim, K. Ohkubo, S. Fukuzumi, J. Mater. Chem. 20 (2010) 475.

[23] S.-O. Kim, D. Sung Chung, H. Cha, J. Wan Jang, Y.-H. Kim, J.-W. Kang, Y.-S. Jeong, C.E. Park, S.-K. Kwon, Sol. Energy Mater. Sol. Cells 95 (2011) 432.

[24] P.A. Troshin, H. Hoppe, J. Renz, M. Egginger, J.Y. Mayorova, A.E. Goryachev, A.S. Peregudov, R.N. Lyubovskaya, G. Gobsch, N.S. Sariciftci, V.F. Razumov, Adv. Funct. Mater. 19 (2009) 779.

[25] F.B. Kooistra, J. Knol, F. Kastenberg, L.M. Popescu, W.J.H. Verhees, J.M. Kroon, J.C. Hummelen, Org. Lett. 9 (2007) 551.

[26] G. Zhao, Y. He, Z. Xu, J. Hou, M. Zhang, J. Min, H.-Y. Chen, M. Ye, Z. Hong, Y. Yang, Y. Li, Adv. Funct. Mater. 20 (2010) 1480.

[27] M. Lenes, G.-J.A.H. Wetzelaer, F.B. Kooistra, S.C. Veenstra, J.C. Hummelen, P.W.M. Blom, Adv. Mater. 20 (2008) 2116.
[28] M. Lenes, S.W. Shelton, A.B. Sieval, D.F. Kronholm, J.C. Hummelen, P.W.M. Blom, Adv. Funct. Mater. 19 (2009) 3002.

[29] Y. He, H.-Y. Chen, J. Hou, Y. Li, J. Am. Chem. Soc. 132 (2010) 1377.

[30] X. Meng, W. Zhang, Z.A. Tan, C. Du, C. Li, Z. Bo, Y. Li, X. Yang, M. Zhen, F. Jiang, J. Zheng, T. Wang, L. Jiang, C. Shu, C. Wang, Chem. Commun. 48 (2012) 425.

[31] Y.-J. Cheng, M.-H. Liao, C.-Y. Chang, W.-S. Kao, C.-E. Wu, C.-S. Hsu, Chem. Mater. 23 (2011) 4056.

[32] C. Zhang, S. Chen, Z. Xiao, Q. Zuo, L. Ding, Org. Lett. 14 (2012) 1508.

[33] C.-L. Chang, C.-W. Liang, J.-J. Syu, L. Wang, M.-k. Leung, Sol. Energy Mater. Sol. Cells 95 (2011) 2371

[34] (a) Y. He, H.-Y. Chen, G. Zhao, J. Hou, Y. Li, Sol. Energy Mater. Sol. Cells 95 (2011) 899;

(b) Y. He, H.-Y. Chen, G. Zhao, J. Hou, Y. Li, Sol. Energy Mater. Sol. Cells 95 (2011) 1762.

[35] L.-L. Deng, J. Feng, L.-C. Sun, S. Wang, S.-L. Xie, S.-Y. Xie, R.-B. Huang, L.-S. Zheng, Sol. Energy Mater. Sol. Cells 104 (2012) 113.

[36] J. Huang, G. Li, Y. Yang, Appl. Phys. Lett. 87 (2005) 112105

[37] J. Peet, J.Y. Kim, N.E. Coates, W. Ma, D. Moses, A.J. Heeger, G.C. Bazan, Nat. Mater. 6 (2007) 497.

[38] J.K. Lee, W.l. Ma, C.J. Brabec, J. Yuen, J.S. Moon, J.Y. Kim, K. Lee, G.C. Bazan, A.J. Heeger, J. Am. Chem. Soc. 130 (2008) 3619.

[39] G. Li, V. Shrotriya, J. Huang, Y. Yao, T. Moriarty, K. Emery, Y. Yang, Nat. Mater. 4 (2005) 864.

[40] G. Zhao, Y. He, Y. Li, Adv. Mater. 22 (2010) 4355.

[41] (a) R.P. Qin, W.W. Li, C.H. Li, C. Du, C. Veit, H.F. Schleiermacher, M. Andersson, Z.S. Bo, Z.P. Liu, O. Inganäs, U. Wuerfel, F.L. Zhang, J. Am. Chem. Soc. 131 (2009) 14612;

(b) J.C. Bijleveld, V.S. Gevaerts, D.D. Nuzzo, M. Turbiez, S.G.J. Mathijssen, D.M. de Leeuw, M.M. Wienk, R.A.J. Janssen, Adv. Mater. 22 (2010) E242. 